Copyright (C) The Author(s), 2020. Published by Cambridge University Press on behalf of The Canadian Journal of Neurological Sciences Inc.

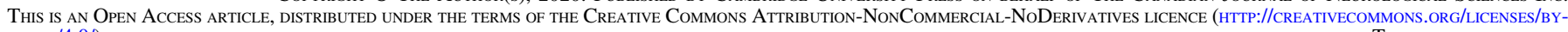

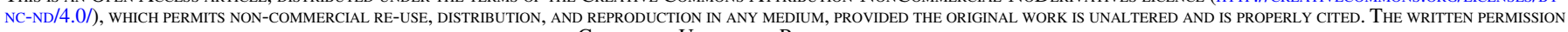

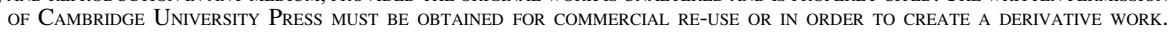

\title{
Neurological Manifestations in COVID-19 Infection: A Systematic Review and Meta-Analysis
}

\author{
Maria Epifania V. Collantes*, Adrian I. Espiritu*, Marie Charmaine C. Sy, \\ Veeda Michelle M. Anlacan, Roland Dominic G. Jamora
}

\begin{abstract}
Background: Growing evidence showed that coronavirus disease 2019 (COVID-19) infection may present with neurological manifestations. This review aimed to determine the neurological manifestations and complications in COVID-19. Methods: We conducted a systematic review and meta-analysis that included cohort and case series/reports involving a population of patients confirmed with COVID-19 infection and their neurologic manifestations. We searched the following electronic databases until April 18, 2020: PubMed, Embase, Scopus, and World Health Organization database (PROSPERO registration number: CRD42020180658). Results: From 403 articles identified, 49 studies involving a total of 6,335 confirmed COVID-19 cases were included. The random-effects modeling analysis for each neurological symptom showed the following proportional point estimates with $95 \%$ confidence intervals: "headache" $\left(0.12 ; 0.10-0.14 ; I^{2}=77 \%\right)$, "dizziness" (0.08; 0.05-0.12; $\left.I^{2}=82 \%\right)$, "headache and dizziness" $\left(0.09 ; 0.06-0.13 ; I^{2}=0 \%\right)$, "nausea" $\left(0.07 ; 0.04-0.11 ; I^{2}=79 \%\right)$, "vomiting" (0.05; 0.03-0.08; $\left.I^{2}=74 \%\right)$, "nausea and vomiting" $\left(0.06 ; 0.03-0.11 ; I^{2}=83 \%\right)$, "confusion" $\left(0.05 ; 0.02-0.14 ; I^{2}=86 \%\right)$, and "myalgia" $\left(0.21 ; 0.18-0.25 ; I^{2}=85 \%\right)$. The most common neurological complication associated with COVID-19 infection was vascular disorders $(n=23)$; other associated conditions were encephalopathy $(n=3)$, encephalitis $(n=1)$, oculomotor nerve palsy $(n=1)$, isolated sudden-onset anosmia $(n=1)$, Guillain-Barré syndrome $(n=1)$, and Miller-Fisher syndrome $(n=2)$. Most patients with neurological complications survived $(n=14)$; a considerable number of patients died $(n=7)$; and the rest had unclear outcomes $(n=12)$. Conclusion: This review revealed that neurologic involvement may manifest in COVID-19 infection. What has initially been thought of as a primarily respiratory illness has evolved into a wide-ranging multi-organ disease.
\end{abstract}

RÉSUMÉ : Examen systématique et méta-analyse des symptômes neurologiques liés à une infection à la COVID-19. Contexte : Des preuves de plus en plus nombreuses indiquent qu'une infection à la COVID-19 peut être accompagnée de symptômes neurologiques. Cette étude entend donc déterminer la nature de ces symptômes de même que les complications qui peuvent survenir. Méthodes : Pour ce faire, nous avons effectué un examen systématique et une méta-analyse portant sur une cohorte de patients et sur une série de cas pour lesquels une infection à la COVID-19, accompagnée de symptômes neurologiques, avait été confirmée. En plus de la base de données de l'OMS (numéro d'enregistrement PROSPERO : CRD42020180658), nous avons également interrogé les bases de données électroniques suivantes, et ce, jusqu'au 18 avril 2020 : PubMed, Embase et Scopus. Résultats : Sur un total de 403 articles répertoriés, 49 études impliquant un total de 6335 cas confirmés de COVID-19 ont été inclues à des fins d'analyse. Une analyse de la modélisation des effets aléatoires (random effect modeling analysis) pour chaque symptôme neurologique a révélé les estimations ponctuelles proportionnelles (proportional point estimates) suivantes en fonction d'un intervalle de confiance de $95 \%$ : « maux de tête » $(0,12 ; 0,10$ - 0,14 ; $\left.\mathrm{I}^{2}=77 \%\right)$, « étourdissements » $\left(0,08 ; 0,05-0,12 ; \mathrm{I}^{2}=82 \%\right)$, « maux de tête et étourdissements » $\left(0,09 ; 0,06-0,13 ; \mathrm{I}^{2}=0 \%\right)$, « nausées » $\left(0,07 ; 0,04-0,11 ; \mathrm{I}^{2}=79 \%\right)$, «vomissements » $\left(0,05 ; 0,03-0,08 ; \mathrm{I}^{2}=74 \%\right)$, « nausées et vomissements » $\left(0,06 ; 0,03-0,11 ; \mathrm{I}^{2}=83 \%\right)$, « confusion» $\left(0,05 ; 0,02-0,14 ; \mathrm{I}^{2}=86 \%\right)$ et «myalgie» $\left(0,21 ; 0,18-0,25 ; \mathrm{I}^{2}=85 \%\right)$. Les complications neurologiques les plus couramment associées aux cas d'infection à la COVID-19 ont été les troubles vasculaires $(\mathrm{n}=23)$. D'autres complications ont aussi été évoquées : encéphalopathie $(\mathrm{n}=3)$, encéphalite $(\mathrm{n}=1)$, paralysie du nerf oculomoteur $(\mathrm{n}=1)$, anosmie subite survenant de façon isolée $(\mathrm{n}=1)$, syndrome de Guillain-Barré $(\mathrm{n}=1)$ et syndrome de Miller-Fisher $(\mathrm{n}=2)$. Si la plupart des patients aux prises avec des complications neurologiques ont survécu $(\mathrm{n}=14)$, un nombre important de patients sont décédés $(n=7)$ tandis que d'autres ont vu leur état de santé évoluer de façon incertaine $(n=12)$. Conclusion : Cette étude révèle en somme que des symptômes d'ordre neurologique peuvent être liés à des cas d'infection à la COVID-19. Considérées à l'origine comme étant essentiellement de nature respiratoire, les infections à la COVID-19 ont fini par être envisagées comme des infections de plus grande envergure qui peuvent affecter de nombreux organes.

Keywords: COVID-19, Neurological manifestations, Outcomes, Systematic review, Meta-analysis

doi: $10.1017 /$ cjn.2020.146

Can J Neurol Sci. 2021; 48: 66-76

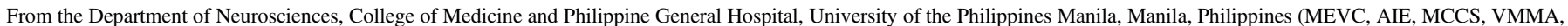
RDGJ); and Department of Clinical Epidemiology, College of Medicine, University of the Philippines Manila, Manila, Philippines (AIE)

Received June 9, 2020. Final Revisions Submitted June 30, 2020. Date of Acceptance July 2, 2020.

*Joint first authors

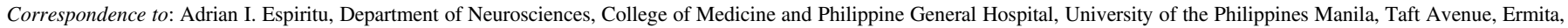
Manila, Philippines, 1000. Email: aiespiritu@up.edu.ph 


\section{INTRODUCTION}

Coronavirus disease 2019 (COVID-19) infection usually presents with fever, colds, throat pains, diarrhea, and respiratory symptoms. ${ }^{1}$ However, growing evidence show that the infection can present with atypical symptoms such as headache, dizziness, seizures, anosmia, stroke, and impaired consciousness. ${ }^{1,2}$ In a case series in Wuhan, China, 36.4\% presented with central nervous system (CNS) symptoms, $8.9 \%$ with peripheral nervous symptoms, and $10.7 \%$ with skeletal muscle symptoms. ${ }^{3}$

A previous systematic review on the CNS manifestations of COVID-19 has been published that involved six studies with primary data. ${ }^{4}$ However, decelerating the COVID-19 global pandemic and filling knowledge gaps necessitate pooling of new and emerging daily research output regarding the neurological involvement in COVID-19 infection. ${ }^{5}$ This current systematic review and meta-analysis aimed to determine the neurological manifestations and complications, including laboratory findings, and outcomes among patients with COVID-19 infection.

\section{Methodology}

This review complied with the Preferred Reporting Items for Systematic reviews and Meta-analyses. ${ }^{6}$ The protocol was registered in PROSPERO (registration number: CRD42020180658).

\section{Criteria for Selection of Studies}

We considered studies with the following designs: cohort, case series/ reports. We considered studies that included a population of patients confirmed with COVID-19 infection according to the established diagnostic criteria. ${ }^{7,8}$ We included studies that enrolled a population of adult and pediatric patients with information on the frequencies and proportions of neurological symptoms/signs, new-onset neurological disorders/complications associated with COVID-19 infection and their outcomes (e.g., recovered/died). No restrictions were implemented on sex and ethnicity of the population. We excluded studies that were reported as abstract-only with no full texts available and non-English articles.

\section{Search Methods for the Identification and Selection of Studies}

Three investigators (MEVC, AIE, MCCS) searched the following major electronic healthcare databases until April 18, 2020 for relevant studies: PubMed by MEDLINE, Embase, Scopus, and the World Health Organization (WHO) database. We used the following general and MeSH terms: ["Coronavirus disease 2019" OR "Novel coronavirus" OR severe acute respiratory syndrome coronavirus 2 ("SARS-CoV-2") OR "COVID-19" OR "2019-nCOV”] AND ["Brain" OR "Spine" OR "Meninges" OR "Central nervous system" OR "Peripheral nervous system" OR "Muscles" or "Neuromuscular junction" OR "Neurologic manifestations"]. To ensure literature saturation, we looked into the references of all identified relevant articles and narrative reviews/systematic reviews and/or meta-analysis for consideration to be included in this current review.

Three investigators (MEVC, AIE, and MCCS) screened for articles using predetermined screening criteria. Relevant articles were retrieved in full text and were subjected to the eligibility criteria. The studies that fulfilled the eligibility criteria were included in the qualitative and quantitative analyses. Any disagreements in the inclusion of the studies were resolved by consensus with the other two investigators (RDGJ and VMMA).

\section{Methodological Assessment of Included Studies}

The Murad tool was used to evaluate the risk of bias in noncomparative cohorts and case series/ reports. ${ }^{9}$ We considered "poor," "moderate," or "good" quality when 3 or fewer, 4 , or 5 of the criteria were fulfilled, respectively. Three investigators (MEVC, VMMA, and RDGJ) evaluated the methodological quality of the included studies; discrepancies were resolved by consensus with the other two investigators (AIE and MCCS).

\section{Data Collection}

Three investigators (MEVC, MCCS, and AIE) extracted the data from the eligible studies, and any discrepancies were resolved by involvement of the other two investigators (VMMA and RDGJ). For each study, the following information was recorded: author and year, publication date, study design, study duration, setting, number of included patients, age, sex, disease severity, comorbidity, neurologic symptoms, neurologic disorders/ complications and associated laboratory findings, and outcomes.

\section{Data Analysis and Synthesis}

We used frequencies and proportions for categorical variables and means (standard deviation) or median (range) for continuous variables. Data were pooled and expressed in $95 \%$ confidence intervals (CIs). The unit of analysis used was the individual patient.

All included studies were analyzed qualitatively. We performed the meta-analysis using the following $\mathrm{R}$ (Version 3.6.3) packages: metafor, meta, and weightr. Meta-analysis was conducted for studies with $>5$ included patients. The proportions were pooled by random-effects model estimated using the DerSimonian and Laird method. Heterogeneity was evaluated using chi-squared test $\left(\chi^{2} ; p\right.$-value $<0.10$ to detect significant heterogeneity) and $I^{2}$ tests with $>25 \%,>50 \%$, and $>75 \%$ considered as low, moderate, or high degree of heterogeneity, respectively. Funnel plots were constructed for neurological symptoms with more than five study components to visually evaluate publication bias with Egger's regression tests conducted to quantitatively assess this bias ( $p$-value $<0.05$ considered statistically significant). If publication bias was suspected, the trim-and-fill method was employed to adjust for potentially missing data in the funnel plot's asymmetry.

\section{Results}

A total of 403 journal articles (MEDLINE by PubMed: 161; Scopus: 126; Embase: 30; WHO Database: 86) were identified using the search strategy. After duplicates were removed, 325 titles and abstracts were screened. After exclusion of 262 articles that did not fulfill the screening criteria, 63 full-text reports were assessed for eligibility. A total of 49 articles fulfilled our inclusion criteria. Among these studies, 35 articles were included in the quantitative synthesis. The diagrammatic flow of information for this review is shown in Figure 1.

One prospective study ${ }^{10}, 35$ retrospective studies ${ }^{1,3,11-43}$, and 13 case report/series ${ }^{44-56}$ with information from a total of 6,335 individuals with COVID-19 infection were involved in this 


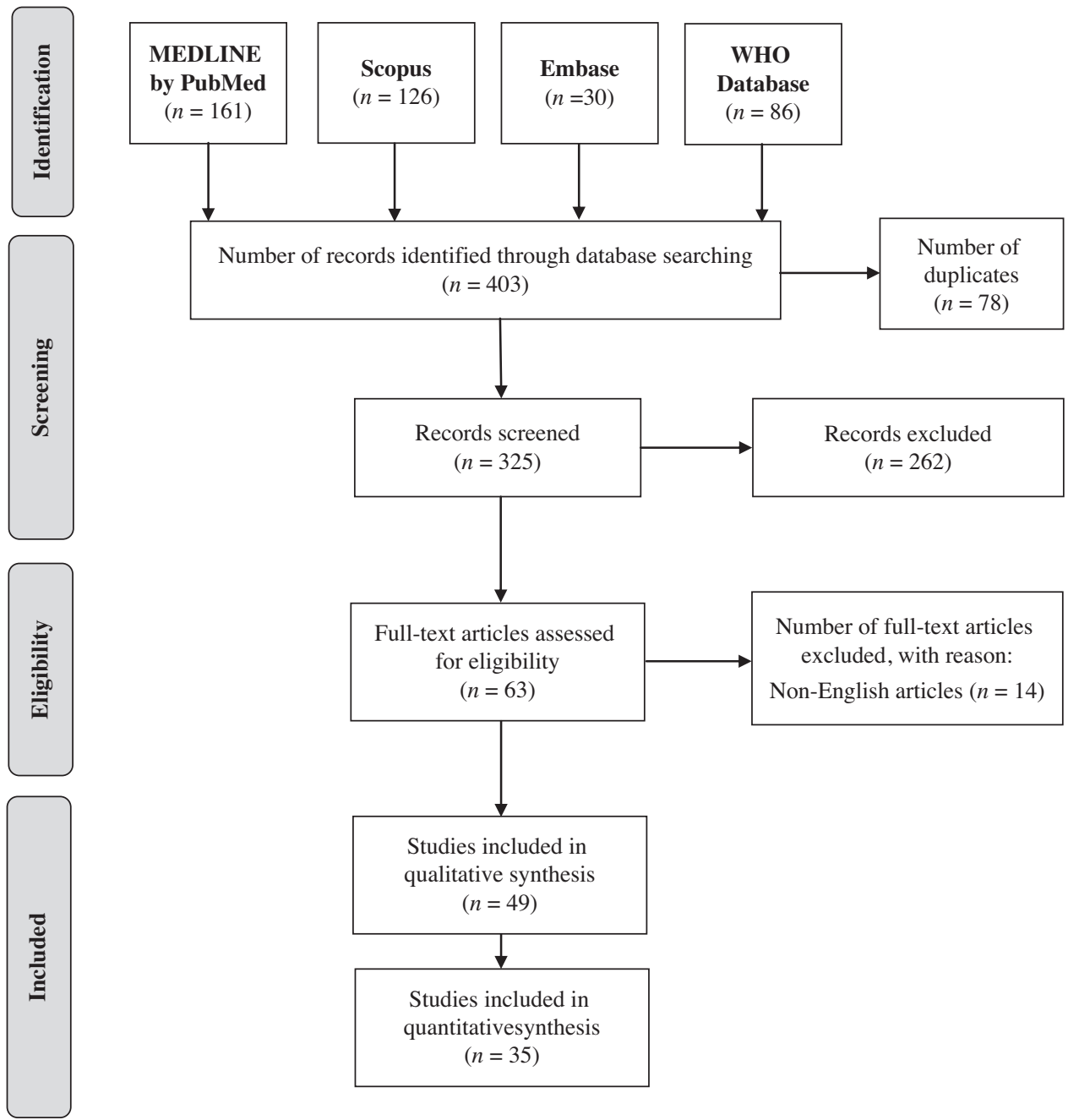

Figure 1: Flow diagram of information for the selection of relevant articles.

review. Patient data from the included studies were obtained from various countries, as follows: China, France, India, Iran, Japan, South Korea, Spain, Thailand, and the USA. The sample size for each study ranged from 1 to 1099 patients. The features of the included studies and enrolled patients are presented in Table 1.

All studies enrolled patients confirmed with COVID-19 infection using clinical criteria corroborated with a positive test in SARS-CoV-2 reverse transcription polymerase chain reaction (RT-PCR) using sputum or nasopharynx swabs samples according to the recommendations of the WHO. The age of patients ranged from 1 to 94 years, with an overall female-to-male ratio of 1:1.2. The spectrum of COVID-19 disease severity was remarkably diverse and reported in varying definitions of categories of gravity of infection. All studies enrolled more stable/mild/ nonsevere cases with a proportion approximately ranging from 50 to $80 \%$; with severe or critical cases varying from 5 to $50 \%$. Ranges of proportions of described comorbidities in the studies were remarkably varied, as follows: hypertension $(4.5 \%-3 \%)$, diabetes $(2 \%-27 \%)$, chronic lung disease $(1 \%-11 \%)$, cardiovascular and cerebrovascular diseases $(1 \%-40 \%)$, gastrointestinal disease $(1 \%-15 \%)$, liver disease $(1 \%-11 \%)$, kidney disease
$(1 \%-17 \%)$, endocrine disease $(5 \%-13 \%)$, malignancy $(1 \%-7 \%)$, and others.

There were 8, 10, and 31 studies deemed with "good," "moderate," and "poor" methodological quality, respectively (see Table 1). Most studies had limitations due to deficient representativeness of the cases related to small sample size and uncertainties in attempts to exclude other diagnoses.

The random-effects modeling analysis for each neurological symptom reported in patients with COVID-19 infection showed the following overall point estimate of proportions with corresponding 95\% CI, number of studies assessed, and the overall number patients with the neurological symptom evaluated divided by the total number of patients analyzed, respectively (see Table 2): "headache" (0.12, 95\% CI 0.10-0.14; 24 studies; 586/4,882), "dizziness" (0.08, 95\% CI 0.05-0.12; 6 studies; 132/1,458), "headache and dizziness" (0.09, 95\% CI 0.06-0.13; 3 studies; 22/256), "nausea" (0.07, 95\% CI 0.04-0.11; 7 studies; 77/1,026), "vomiting" (0.05, 95\% CI 0.03-0.08; 9 studies; $116 / 2,409)$, "nausea and vomiting" (0.06, 95\% CI $0.03-0.11$; 9 studies; 100/1,796), "confusion" (0.05, 95\% CI $0.02-0.14$; 2 studies; 26/647), and "myalgia" (0.21, 95\% CI $0.18-0.25$; 25 studies; 952/5,155). The forest plots for all the reported 
Table 1: Features of the included studies and population, reported neurologic symptoms, and quality assessment

\begin{tabular}{|c|c|c|c|c|c|c|c|}
\hline Study & Sample (n) & Setting & Study design & $\begin{array}{c}\text { Mean or median } \\
\text { age (SD or } \\
\text { range) }\end{array}$ & $\begin{array}{c}\text { Female:male } \\
\text { ratio }\end{array}$ & Neurologic symptoms reported & $\begin{array}{l}\text { Quality } \\
\text { assessment* }\end{array}$ \\
\hline Chang et al. ${ }^{21}$ & 13 & Beijing, China & Retrospective & $34(14)$ & $1: 3.3$ & Headache and myalgia & Poor \\
\hline Chen et al. ${ }^{32}$ & 99 & Wuhan, China & Retrospective & $55.5(13.1)$ & $1: 2.1$ & $\begin{array}{l}\text { Muscle ache, confusion, headache, } \\
\text { nausea, and vomiting }\end{array}$ & Moderate \\
\hline Chen et al. ${ }^{37}$ & 249 & Wuhan, China & Retrospective & $62(18)$ & $1: 1.7$ & $\begin{array}{l}\text { Myalgia, headache, nausea, dizziness, } \\
\text { and vomiting }\end{array}$ & Moderate \\
\hline Chen et al. ${ }^{38}$ & 203 & Wuhan, China & Retrospective & $54(20-91)$ & $1: 1.1$ & $\begin{array}{l}\text { Myalgia, headache, dizziness, nausea, } \\
\text { and vomiting }\end{array}$ & Moderate \\
\hline Chung et al. ${ }^{39}$ & 21 & $\begin{array}{l}\text { Zhuhai, Nanchang } \\
\text { and Qingdao, China }\end{array}$ & Retrospective & $51(14)$ & $1: 1.6$ & Muscle soreness, headache, and nausea & Poor \\
\hline Du et al. ${ }^{10}$ & 179 & Wuhan, China & Prospective & $57.6(13.7)$ & $1: 1.2$ & Myalgia and headache & Poor \\
\hline Feng et al. ${ }^{40}$ & 476 & $\begin{array}{l}\text { Wuhan and Anhui } \\
\text { Province, China }\end{array}$ & Retrospective & $53(40-64)$ & $1: 1.3$ & Myalgia and neurological symptoms & Moderate \\
\hline Filatov et al. ${ }^{44}$ & 1 & Florida, USA & Case report & 74 & $0: 1$ & $\begin{array}{l}\text { Headache, altered mental status, } \\
\text { fever, and cough }\end{array}$ & Poor \\
\hline Gane et al. ${ }^{45}$ & 1 & London, UK & Case report & 48 & $0: 1$ & Isolated anosmia & Poor \\
\hline Guan et al. ${ }^{1}$ & 1099 & China & Retrospective & $47(35-58)$ & $1: 2.4$ & $\begin{array}{l}\text { Myalgia, headache, and nausea/ } \\
\text { vomiting }\end{array}$ & Moderate \\
\hline Gupta et al. ${ }^{43}$ & 21 & New Delhi, India & Retrospective & $40.3(16-73)$ & $1: 2$ & Headache & Poor \\
\hline $\begin{array}{l}\text { Gutiérrez-Ortiz } \\
\text { et al. }^{56}\end{array}$ & 2 & Madrid, Spain & Case series & 38 and 50 & $0: 2$ & Anosmia and ageusia & Poor \\
\hline Helms et al. ${ }^{41}$ & 58 & Strasbourg, France & Retrospective & 63 & NR & $\begin{array}{l}\text { Agitation, corticospinal tract signs, and } \\
\text { dysexecutive syndrome }\end{array}$ & Poor \\
\hline Huang et al. ${ }^{42}$ & 41 & Wuhan, China & Retrospective & $49(41-58)$ & $1: 2.7$ & Myalgia and headache & Moderate \\
\hline Karimi et al. ${ }^{48}$ & 1 & Sari, Iran & Case report & 30 & $1: 0$ & Seizure & Poor \\
\hline Kim et al. ${ }^{11}$ & 28 & South Korea & Retrospective & $42.6(13.4)$ & $1: 1.2$ & Headache and myalgia & Moderate \\
\hline Lei et al. ${ }^{12}$ & 20 & Guangzhou, China & Retrospective & $43.2(14)$ & $1: 1$ & Myalgia and nausea/vomiting & Poor \\
\hline Li et al. ${ }^{13}$ & 548 & Wuhan, China & Retrospective & $60(48-69)$ & $1: 1$ & $\begin{array}{l}\text { Myalgia, headache, dizziness, } \\
\text { vomiting, and confusion }\end{array}$ & Poor \\
\hline Li et al. ${ }^{14}$ & 221 & Wuhan, China & Retrospective & $53.3(15.9)$ & $1: 2.5$ & NR & Poor \\
\hline Liu et al. ${ }^{15}$ & 137 & Wuhan, China & Retrospective & $57(20-83)$ & $1.2: 1$ & Myalgia and headache & Poor \\
\hline Liu et al. ${ }^{16}$ & 12 & Shenzhen, China. & Retrospective & $53.7(10-72)$ & $1: 2$ & Myalgia and nausea/vomiting & Poor \\
\hline Mao et al. ${ }^{3}$ & 214 & Wuhan, China & Retrospective & $52.7(15.5)$ & $1.5: 1$ & $\begin{array}{l}\text { Dizziness, headache, impaired } \\
\text { consciousness, acute cerebrovascular } \\
\text { disease, seizure, ataxia, impairment } \\
\text { of taste, impairment of smell, nerve } \\
\text { pain, impairment of vision, and } \\
\text { skeletal muscle injury }\end{array}$ & Moderate \\
\hline $\begin{array}{l}\text { Moriguchi } \\
\text { et al. }\end{array}$ & 1 & Yamanashi, Japan & Case report & 24 & $0: 1$ & $\begin{array}{l}\text { Headache, convulsion, and impaired } \\
\text { consciousness }\end{array}$ & Poor \\
\hline Pan et al. ${ }^{17}$ & 21 & Wuhan, China & Retrospective & $40(9)$ & $2.5: 1$ & Myalgia & Poor \\
\hline Poyiadji et al. ${ }^{47}$ & 1 & Detroit, USA & Case report & NR & $1: 0$ & Altered mental status & Poor \\
\hline $\begin{array}{l}\text { Sharifi-Razavi } \\
\text { et al. }^{50}\end{array}$ & 1 & Sari, Iran & Case report & 79 & $0: 1$ & Acute loss of consciousness & Poor \\
\hline Shen et al. ${ }^{18}$ & 119 & Xiangyang, China & Retrospective & $49(38-61)$ & $1.1: 1$ & Headache, nausea, and vomiting & Poor \\
\hline Shi et al. ${ }^{19}$ & 81 & Wuhan, China & Retrospective & $49.5(11)$ & $1: 1.1$ & Headache, vomiting, and dizziness & Poor \\
\hline Song et al. ${ }^{20}$ & 51 & Shanghai, China & Retrospective & $49.6(16)$ & $1: 1$ & $\begin{array}{l}\text { Myalgia, headache, dizziness, and } \\
\text { nausea/vomiting }\end{array}$ & Poor \\
\hline Tian et al. $^{22}$ & 262 & Beijing, China & Retrospective & $47.5(1-94)$ & $1: 1.1$ & Headache & Moderate \\
\hline Vu et al. ${ }^{51}$ & 1 & New York, USA & Case report & 30 & $0: 1$ & $\begin{array}{l}\text { Dysarthria, right hemiparesis, and right } \\
\text { facial droop }\end{array}$ & Poor \\
\hline
\end{tabular}


Table 1: (Continued)

\begin{tabular}{|c|c|c|c|c|c|c|c|}
\hline Study & Sample (n) & Setting & Study design & $\begin{array}{l}\text { Mean or median } \\
\text { age (SD or } \\
\text { range) } \\
\end{array}$ & $\begin{array}{l}\text { Female:male } \\
\text { ratio }\end{array}$ & Neurologic symptoms reported & $\begin{array}{l}\text { Quality } \\
\text { assessment* }\end{array}$ \\
\hline Wang et al. ${ }^{23}$ & 138 & Wuhan, China & Retrospective & $56(42-68)$ & $1: 1.1$ & $\begin{array}{l}\text { Myalgia, nausea, dizziness, headache, } \\
\text { and vomiting }\end{array}$ & Good \\
\hline Wang et al. ${ }^{24}$ & 125 & $\begin{array}{l}\text { Anhui Province, } \\
\text { China }\end{array}$ & Retrospective & $38.8(13.79)$ & $1: 1.3$ & $\begin{array}{l}\text { Myalgia, nausea/vomiting, and } \\
\text { headache/dizziness }\end{array}$ & Good \\
\hline Wang et al. ${ }^{26}$ & 1012 & Wuhan, China & Retrospective & $50(16-89)$ & $1: 1.1$ & Myalgia, vomiting, and headache & Good \\
\hline Wang et al. ${ }^{25}$ & 4 & Shanghai, China & Retrospective & $44.3(19-63)$ & $1: 3$ & Dizziness & Poor \\
\hline Pongpirul et al. ${ }^{27}$ & 11 & Bangkok, Thailand & Retrospective & $61(28-74)$ & NR & Headache and vomiting & Poor \\
\hline Wei et al. ${ }^{52}$ & 1 & Hubei, China & Case report & 62 & $0: 1$ & Diplopia and left eyelid drooping & Poor \\
\hline Wu et al. ${ }^{28}$ & 80 & $\begin{array}{l}\text { Jiangsu Province, } \\
\text { China }\end{array}$ & Retrospective & $46.1(15.4)$ & $1.1: 1$ & $\begin{array}{l}\text { Muscle ache, headache and mental } \\
\text { disorder symptoms, nausea, and } \\
\text { vomiting }\end{array}$ & Moderate \\
\hline Wu et al. ${ }^{29}$ & 80 & Chongqing, China & Retrospective & $44(11)$ & $1: 1.1$ & Muscle ache, headache, and dizziness & Good \\
\hline $\mathrm{Xu}$ et al. ${ }^{30}$ & 90 & $\begin{array}{l}\text { Guangdong Province, } \\
\text { China }\end{array}$ & Retrospective & $50(18-86)$ & $1: 1.3$ & $\begin{array}{l}\text { Mylagia, headache, nausea, and } \\
\text { vomiting }\end{array}$ & Moderate \\
\hline $\mathrm{Xu}$ et $\mathrm{al}^{31}$ & 62 & $\begin{array}{l}\text { Zhejiang Province, } \\
\text { China }\end{array}$ & Retrospective & $41(32-52)$ & $1: 1.3$ & Myalgia and headache & Good \\
\hline Yang et al. ${ }^{33}$ & 52 & Wuhan, China & Retrospective & $59.7(13.3)$ & $1: 2.1$ & Myalgia, headache, and vomiting & Good \\
\hline Ye et al. ${ }^{53}$ & 1 & Wuhan, China & Case report & NR & $0: 1$ & Confusion & Poor \\
\hline Yin et al. ${ }^{53}$ & 1 & Wuhan, China & Case report & 64 & $0: 1$ & Insomnia, lethargic, and unresponsive & Poor \\
\hline Zhang et al. ${ }^{34}$ & 140 & Wuhan, China & Retrospective & $57(25-87)$ & $1: 1$ & Nausea & Poor \\
\hline Zhang et al. ${ }^{46}$ & 3 & Wuhan, China & Case series & $68(65-70)$ & $1: 2$ & Headache & Poor \\
\hline Zhao et al. ${ }^{55}$ & 1 & Wuhan, China & Case report & 61 & 1:0 & Weakness of both legs & Poor \\
\hline Zheng et al. ${ }^{35}$ & 161 & Hunan, China & Retrospective & $45(33.5-57)$ & $1: 1$ & Mylagia, headache, and nausea & Good \\
\hline Zhou et al. ${ }^{36}$ & 191 & Wuhan, China & Retrospective & $56(46-67)$ & $1: 1.6$ & Myalgia, nausea, and vomiting & Good \\
\hline
\end{tabular}

$\mathrm{NR}=$ not reported.

*Methodological quality assessment using the Murad tool: "Good" (5 points), "Moderate" (4 point), "Poor" (3 or lower points).

neurological symptoms are shown in Figure 2. Other less commonly reported neurological symptoms are presented in Table 1.

Nearly all symptom analyses detected statistically significant heterogeneity ( $p$-value $<0.10)$ with a high degree of heterogeneity $\left(I^{2}>75 \%\right)$ excluding the symptom of "headache and dizziness" ( $p$-value $=0.71 ; I^{2}=0 \%$ ) (see Figure 2$)$. A subgroup analysis to explore possible heterogeneity source could not be done due to insufficient presented data in the included studies.

The funnel plots showed asymmetry in the "dizziness" and "nausea" symptoms and corroborated using Egger's regression test (see Supplementary Material 1; funnel plot B: $p$-value $=0.0025$; funnel plot $C: p$-value $=0.0227$ ); all the other funnel plots and corresponding regression tests did not show statistically significant asymmetry ( $p$-values $>0.05$ ). Results from the trimand-fold method demonstrated that two studies and three studies necessary were missed on the right side of the plots in the "dizziness" and "nausea" symptoms, respectively (see Supplementary Material $1 \mathrm{G}$ to $\mathrm{H}$ ); the adjusted random-effects pooled proportion were 0.11 (95\% CI $0.06-0.17)$ and 0.10 (95\% CI $0.06-0.17$ ) for "dizziness" and "nausea" symptoms, respectively.

A total of 14 studies with 33 patients were identified that described new-onset neurological disorders/complications linked to COVID-19 infection with some detail (see Table 3). Vascular disorders were noted to be most frequent $(n=23 ; 69.7 \%)$; these presented as acute cerebral infarction $(n=18)$, acute intracerebral hemorrhage $(n=4)$, and cerebral venous sinus thrombosis $(n=1)$; eight cases survived and five cases died. ${ }^{3,14,46,50,51}$ Four case reports described patients who manifested with encephalopathy/ encephalitis, with two patients recovering. ${ }^{44,49,53,54}$ A COVID-19 case with documented acute necrotizing hemorrhagic encephalopathy presented as altered mental status but the patient's outcome was unclear. ${ }^{47}$ Cranial and peripheral nerves were also deemed affected by COVID-19 infection as described in a number of patients who had isolated sudden-onset anosmia $(n=1)$, oculomotor nerve palsy $(n=1)$, Miller-Fisher syndrome (MFS; $n=2$ ), and Guillain-Barre syndrome (GBS; $n=1) .{ }^{45,52,55,56}$ Most patients with neurological complications survived $(n=14)$, a considerable number of patients died $(n=7)$ and the rest had unclear outcomes $(n=12)$. Overall, 28 patients $(84.8 \%)$ and 5 patients $(15.2 \%)$ had central and peripheral nervous system involvement, respectively.

Neuroimaging of patients with COVID-19 infection and neurological manifestations using computed tomography or magnetic resonance interval may show leptomeningeal enhancement, localized decreased cerebral blood flow, both ischemic and hemorrhagic strokes, cerebral venous thrombosis, and 
Table 2: Pooled overall estimates of the proportions of various neurological symptoms in COVID-19 infection

\begin{tabular}{l|c|c|c|c}
\hline Neurological symptoms & Number of studies & $\begin{array}{c}\text { Patients with the neurological } \\
\text { symptom }\end{array}$ & $\begin{array}{c}\text { Total number of patients } \\
\text { analyzed }\end{array}$ & Overall estimate* \\
\hline Myalgia & 25 & 952 & 5,155 & $0.21[0.18 ; 0.25]$ \\
\hline Headache & 24 & 586 & 4,882 & $0.12[0.10 ; 0.14]$ \\
\hline Headache and dizziness & 3 & 22 & 256 & $0.09[0.06 ; 0.13]$ \\
\hline Dizziness & 6 & 132 & 1,458 & $0.08[0.05 ; 0.12]$ \\
\hline Nausea & 7 & 77 & 1,026 & $0.07[0.04 ; 0.11]$ \\
\hline Nausea and vomiting & 9 & 100 & 1,796 & $0.06[0.03 ; 0.11]$ \\
\hline Vomiting & 9 & 116 & 2,409 & $0.05[0.03 ; 0.08]$ \\
\hline Confusion & 2 & 26 & 647 & $0.05[0.02 ; 0.14]$ \\
\hline
\end{tabular}

*Expressed as point estimates of the proportions [with 95\% confidence intervals].

hemorrhagic necrotizing encephalopathy. ${ }^{14,41,47}$ Cerebral infarctions in both small and large vessels, including cardioembolic strokes, were also reported. ${ }^{14}$ Electroencephalography (EEG) showed only nonspecific changes. ${ }^{53}$ Cerebrospinal fluid (CSF) studies are often normal with some showing slight elevation in opening pressure and slight increase in mononuclear cells and protein. ${ }^{55}$ The result of CSF RT-PCR is not consistent and depends on the type of test kits and neurological complications. ${ }^{44,49,53,56}$ Only one of nine CSF tested was RT-PCR positive. $^{41,49,53}$ Meningoencephalitis may have a positive CSF RT-PCR, while cerebral infarction may have negative result. ${ }^{41,49}$ Nerve conduction studies (NCS) done in one patient showed delayed distal latencies and absent F-waves, which may indicate a demyelinating neuropathy. ${ }^{55}$

\section{Discussion}

To the best of our knowledge, our review presents the most extensive evaluation of the neurological manifestations of COVID-19 infection with relevant information from 49 studies involving 6,335 patients. Our review provides the first large qualitative and quantitative analyses of neurological symptoms, complications, laboratory findings, and outcomes associated with this condition.

Pooled evidence showed that "myalgia" and "headache" were the most typical neurological symptoms of COVID-19, followed by "headache \& dizziness," "dizziness," "nausea," "nausea and vomiting," "vomiting," and "confusion." Although neurological symptoms arise in COVID-19 infections, its occurrence may be considered low, that is, the upper limit of the $95 \% \mathrm{CI}$ of "myalgia" symptom is 0.25 and the lower limit of the $95 \%$ CI of "confusion" is 0.02). The most common neurological complications associated with this infection were cerebrovascular disorders presenting as acute cerebral infarction or hemorrhage, or cerebral sinus venous thrombosis. Furthermore, other documented COVID-19-related cases were encephalopathy, encephalitis, oculomotor nerve palsy, isolated sudden-onset anosmia, and GBS which included MFS. The performance and need for neurological diagnostic tests may vary and may be determined by clinical examination. Brain imaging of these patients may provide evidence of infarction or hemorrhage in suspected patients with stroke-like syndrome. EEG may show nonspecific findings in patients with encephalitis. CSF studies may show normal parameters, slight opening pressure elevation, and small increase in mononuclear cells and protein, or may provide very low yield in testing for COVID-19 employing the current RT-PCR kits or protocols. A GBS case associated with COVID-19 showed an NCS finding consistent with a demyelinating neuropathy. Many COVID-19 patients with neurological conditions recovered but outcomes of the other reported cases were unclear.

Coronaviruses (CoVs) in general have been known to exhibit neurotropic properties and as such may cause neurological conditions. ${ }^{57}$ There are several possible mechanisms why CoV infections damage the CNS. First is that the genetic material and proteins of several viruses have been detected in the CSF or brain tissues. ${ }^{58}$ A neuronal pathway is another possible route. The virus may lead to the disruption of the nasal epithelium and is released mostly on the apical as well as basolateral side of the epithelial cells and reach the bloodstream or lymph to reach other tissues, including the CNS ${ }^{59,60}$ The viruses can also migrate by infecting motor or sensory nerves, via neuronal transport. ${ }^{61}$ Alveolar gas exchange disorders are caused by viral proliferation in the lung tissue cells. This in turn causes CNS hypoxia, increasing anaerobic metabolism in the brain. ${ }^{57}$ Another mechanism would be immune-mediated. ${ }^{62}$ This is closely related to the development of systemic inflammatory response syndrome. CoV infections can infect macrophages, microglia, and astrocytes. It can activate glial cells and promote a proinflammatory state. ${ }^{63,64}$ Cytokines can cross the blood-brain barrier and are associated with acute necrotizing encephalopathy. ${ }^{47}$ The neurovirulence of $\mathrm{CoV}$ correlates with its ability to induce proinflammatory cytokine signals from astrocytes and microglia. ${ }^{63}$

The brain has been reported to express angiotensin-converting enzyme 2 (ACE2) receptors that have been detected over glial cells and neurons, which makes them a potential target of COVID-19. The spike protein S1 of the SARS-CoV virus enables its attachment to the cell membrane by interacting with host ACE2 receptor. ${ }^{65}$ By binding to ACE2 receptors, they may cause abnormally elevated blood pressure thereby increasing cerebral hemorrhage risk. The SARS-CoV-2 spike protein could interact with ACE2 expressed in the capillary endothelium, possibly causing damage to the blood-brain barrier and gaining entry into the CNS by attacking the vascular system. ${ }^{65}$ Moreover, a 

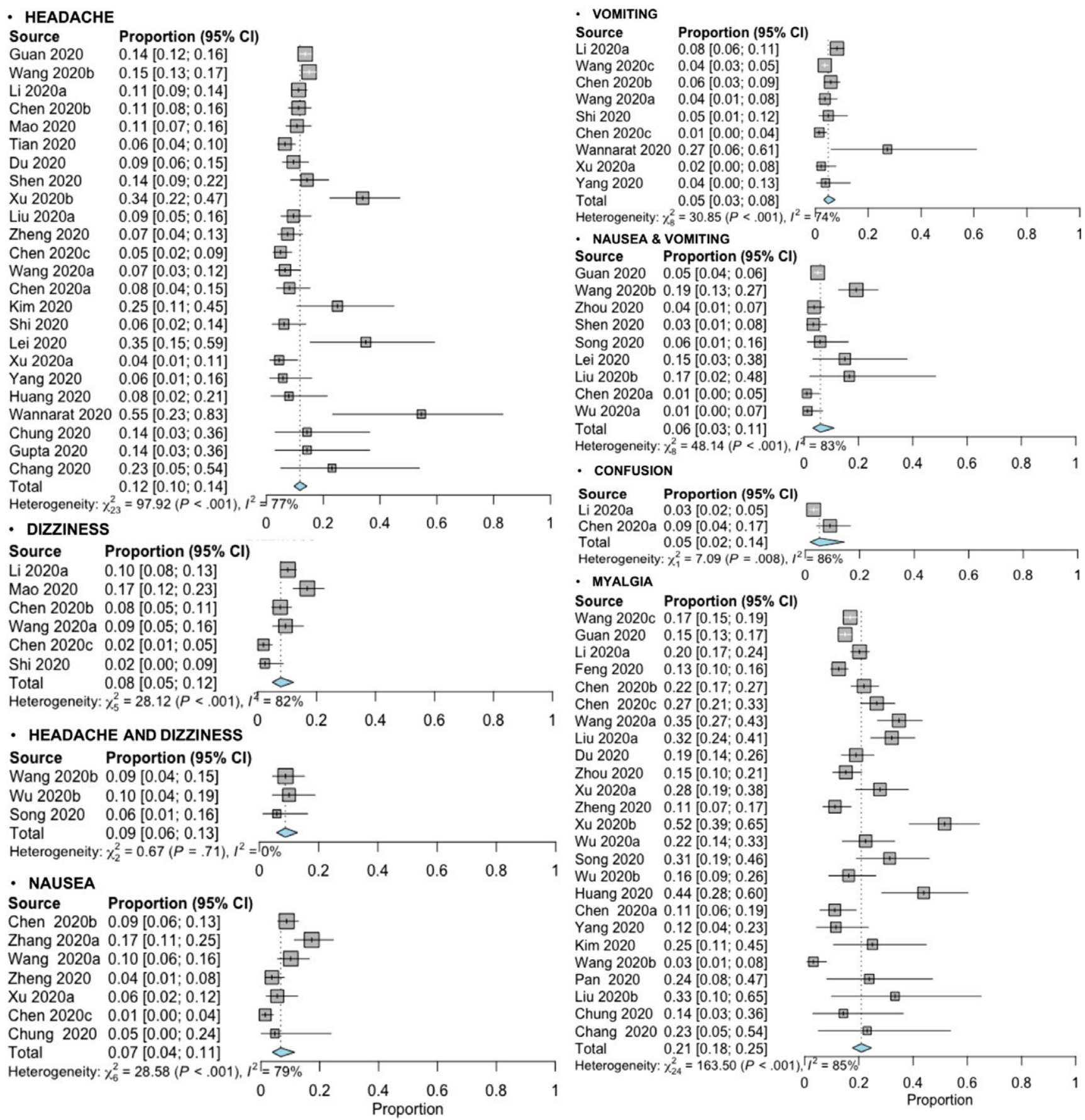

Figure 2: Forest plots of the meta-analysis of proportions for the reported neurological symptoms associated with COVID-19 infection from various study sources.

derangement in coagulation system causing D-dimer and platelet abnormalities are postulated to increase the risk of cerebrovascular diseases. ${ }^{66}$

The statistically significant heterogeneity found in the pooled proportional estimates of the neurological symptoms in this review may stem from clinical variations in age, disease severity, and underlying comorbidities that were difficult to subgroup due to limited information from the published studies. The age range of the population enrolled was wide, and this may lead to variances in the incidence of many neurological symptoms, that is, older individuals tend to have more underlying conditions and therefore, they have the proclivity to report more symptoms. ${ }^{3}$ Majority of the population included in the studies were more substantially represented by patients with stable/ mild/ nonsevere COVID-19 cases compared to severe/critical cases, which could explain the low occurrences of the reported neurological symptoms. It is theorized that individuals with severe COVID-19 infection may have increased probability of developing neurological manifestations such as disturbances in consciousness, skeletal muscle injury, including acute stroke. ${ }^{3}$ Many patients 
Table 3: Neurological disorders or complications associated with COVID-19 infection $(N=33)$

\begin{tabular}{|c|c|c|c|c|}
\hline $\begin{array}{l}\text { Neurological disorder/ } \\
\text { complications }\end{array}$ & Sources & Frequency, $n(\% *)$ & Neurological symptoms & Outcome $(n)$ \\
\hline \multirow{3}{*}{$\begin{array}{l}\text { Acute cerebral } \\
\text { infarction }\end{array}$} & Li et al. ${ }^{14}$ & $11(33.3)$ & NS & Recovered (7); dead (4) \\
\hline & Mao et al. ${ }^{3}$ & $4(12.1)$ & NS & NR (4) \\
\hline & Zhang et al. ${ }^{46}$ & $3(9.1)$ & Headache & NR (3) \\
\hline \multirow{4}{*}{$\begin{array}{l}\text { Acute intracerebral } \\
\text { hemorrhage }\end{array}$} & Li et al. ${ }^{14}$ & $1(3.0)$ & NS & Recovered \\
\hline & Mao et al. ${ }^{3}$ & $1(3.0)$ & NS & Dead \\
\hline & Sharifi-Razavi et al. ${ }^{50}$ & $1(3.0)$ & $\begin{array}{l}\text { Acute loss of consciousness, Glasgow coma scale 7, and bilateral extensor } \\
\text { plantar reflexes }\end{array}$ & NR \\
\hline & Vu et al. ${ }^{51}$ & $1(3.0)$ & Dysarthria, right hemiparesis, and right facial droop & NR \\
\hline $\begin{array}{l}\text { Cerebral sinus venous } \\
\text { thrombosis }\end{array}$ & Li et al. ${ }^{14}$ & $1(3.0)$ & NS & Dead \\
\hline \multirow[t]{2}{*}{ Encephalopathy } & Filatov et al. ${ }^{43}$ & $1(3.0)$ & $\begin{array}{l}\text { Headache, altered mental status, encephalopathic, nonverbal, and unable to } \\
\text { follow any commands }\end{array}$ & NR \\
\hline & Yin et al. ${ }^{54}$ & $1(3.0)$ & $\begin{array}{l}\text { Insomnia, muscle soreness, lethargic and unresponsive, positive bilateral } \\
\text { ankle clonus, lower left limb was positive for the Babinski sign and } \\
\text { Chaddock sign, neck stiffness }\end{array}$ & Recovered \\
\hline $\begin{array}{l}\text { Acute necrotizing } \\
\text { hemorrhagic } \\
\text { encephalopathy }\end{array}$ & Poyiadji et al. ${ }^{47}$ & $1(3.0)$ & Altered mental status & NR \\
\hline \multirow[t]{2}{*}{ Encephalitis } & Moriguchi et al. ${ }^{49}$ & $1(3.0)$ & Headache, convulsion and impaired consciousness, and neck stiffness & NR \\
\hline & Ye et al. ${ }^{53}$ & $1(3.0)$ & Confusion, nuchal rigidity, present extensor plantar response & Recovered \\
\hline Oculomotor nerve palsy & Wei et al. ${ }^{52}$ & $1(3.0)$ & Diplopia and left eyelid drooping & Dead \\
\hline $\begin{array}{l}\text { Isolated sudden-onset } \\
\text { anosmia }\end{array}$ & Gane et al. ${ }^{45}$ & $1(3.0)$ & Impairment of smell & Recovered \\
\hline Miller-Fisher syndrome & Gutiérrez-Ortiz et al. $^{56}$ & $2(6.1)$ & $\begin{array}{l}\text { Anosmia and ageusia, right internuclear ophthalmoparesis, right fascicular } \\
\text { oculomotor palsy, ataxia, and areflexia }\end{array}$ & Recovered (2) \\
\hline $\begin{array}{l}\text { Guillain-Barré } \\
\text { syndrome }\end{array}$ & Zhao et al. ${ }^{55}$ & $1(3.0)$ & $\begin{array}{l}\text { Weakness of both legs, muscle strength } 4 / 5 \text { both arms and } 3 / 5 \text { both legs, } \\
\text { areflexive, sensation to light touch and pinprick was decreased distally }\end{array}$ & Recovered \\
\hline
\end{tabular}

$\mathrm{NR}=$ not reported; NS = not specified.

*Percentages among patients with COVID-19 infection with neurological disorders/complications.

in several studies in this review had broad spectrum of comorbid conditions which may also affect the emergence of some neurological symptoms, complications, and outcomes. ${ }^{37}$ Furthermore, many studies exhibited "poor" methodological quality which may have contributed to the heterogeneity as well. Although heterogeneity may be evident, the authors agreed to pool the data since the main purpose of this review is to provide a reliable general approximation of the point estimates and 95\% CI of the proportions of the neurological symptoms of all patients with COVID-19. These overall measurements reflect the best estimates of the frequencies of the neurological manifestations which are valuable pieces of information that can guide a clinician to appropriately recognize and diagnose COVID-19 infection in a suspected individual. Moreover, combining pertinent data made it feasible to increase the precision of our estimates by increasing the number of the included patients in the quantitative analysis.

The funnel asymmetry detected visually and quantitatively in the pooled analyses of "dizziness" and "nausea" symptoms may suggest the presence of publication bias. However, during this current COVID-19 crisis, any study related to this condition is preferably reviewed and published due to the recognized urgency to characterize and provide solutions to combat this pandemic. ${ }^{67}$ While a skewed funnel plot may arise from publication bias, this phenomenon may also be explained by other reasons, such as exclusion of non-English articles (an acknowledged limitation of this review), clinical heterogeneity, poor methodological design, and chance. ${ }^{68}$

While the evident advantage of this review lies in the inclusion of substantial quantity of studies and patients with COVID-19, its strength also depends on the rigor of the review process. Every step in the review process such as the systematic search for relevant trials, selection of studies, data extraction, data synthesis, and analysis involved at least three investigators; in consensus with the other two investigators, if there were discrepancies. This design was conducted to minimize unanticipated random or systematic error that could transpire if a single investigator managed a certain process in the review. Moreover, a sensitive approach in searching for significant articles was conducted to obtain greater yield records for evaluation. We employed broader, general terms including MeSH terms, and we handsearched the reference lists of relevant studies to ensure literature 
saturation. This strategy allows a more exploratory approach for discovery of significant studies to be included in this review.

However, this review could not capture information from gray literature or unpublished data that were not indexed in the major healthcare electronic databases and from non-English articles. Moreover, this review could only integrate available literature that were mostly retrospective in nature. These studies have inherent recording bias that may potentially obscure the validity of the pooled estimates.

Neurological symptoms such as headache, myalgia, dizziness, and nausea are nonspecific and may be present in other conditions. Thus, a thorough neurological examination and referral may be sought for early recognition, diagnosis, and treatment of neurological complications.

In summary, this systematic review and meta-analysis showed that neurological symptoms such as headache, myalgia, dizziness, and nausea are present in COVID-19; 1 in 10 patients may present with headache and 2 in 10 patients may present with myalgia. The most common neurological complication associated with this infection was cerebrovascular disease. In order to substantiate these findings, the performance of larger and ethically appropriate prospective studies must be undertaken; looking into these signs and symptoms early on, and carefully documenting their complications and outcomes over the full course of the illness.

\section{CONFLict of InTEREST}

None.

\section{Statement of Authorship}

MEVC: Conceptualization, data curation, formal analysis, interpretation of data, writing original draft, writing review, and editing. AIE: Conceptualization, data curation, formal analysis, interpretation of data, writing original draft, writing review, and editing. MCCS: Conceptualization, data curation, formal analysis, interpretation of data, writing original draft, writing review, and editing. VMMA: Conceptualization, data curation, formal analysis, interpretation of data, writing original draft, writing review, and editing. RDGJ: Conceptualization, data curation, formal analysis, interpretation of data, writing original draft, writing review, and editing.

\section{SuPPLementary Material}

To view supplementary material for this article, please visit https://doi.org/10.1017/cjn.2020.146.

\section{REFERENCES}

1. Guan W, Ni Z, Hu Y, et al. Clinical characteristics of coronavirus disease 2019 in China. N Engl J Med [Internet]. 2020;382: 1708-20. Available at: http://www.nejm.org/doi/10.1056/ NEJMoa2002032

2. Jiang F, Deng L, Zhang L, Cai Y, Cheung CW, Xia Z. Review of the clinical characteristics of coronavirus disease 2019 (COVID-19). J Gen Intern Med. 2020;35(5):1545-9.

3. Mao L, Jin $\mathrm{H}$, Wang $\mathrm{M}$, et al. Neurologic manifestations of hospitalized patients with coronavirus disease 2019 in Wuhan, China. JAMA Neurol. 2020;77(6):683-90.

4. Asadi-Pooya A, Simani L. Central nervous system manifestations of COVID-19: a systematic review. J Neurol Sci [Internet]. 2020;
413:116832. Available at: https://linkinghub.elsevier.com/retrieve /pii/S0022510X20301684

5. Chahrour M, Assi S, Bejjani M, et al. A bibliometric analysis of COVID-19 research activity: a call for increased output. Cureus [Internet]. 2020;12(3):e7357. Available at: https://www.cureus. com/articles/29507-a-bibliometric-analysis-of-covid-19-researchactivity-a-call-for-increased-output

6. Liberati A, Altman DG, Tetzlaff J, et al. The PRISMA statement for reporting systematic reviews and meta-analyses of studies that evaluate health care interventions: explanation and elaboration. PLoS Med. 2009;6(7):e1000100.

7. Lu R, Zhao X, Li J, et al. Genomic characterisation and epidemiology of 2019 novel coronavirus: implications for virus origins and receptor binding. Lancet [Internet]. 2020;395(10224):565-74. Available at: https://linkinghub.elsevier.com/retrieve/pii/S01406 73620302518

8. Centers for Disease Control and Prevention. Evaluating and testing persons for coronavirus disease 2019 (COVID-19) [Internet]. 2020 [cited 2020 Apr 7]; Available at: https://www.cdc.gov/ coronavirus/2019-nCoV/hcp/clinical-criteria.html

9. Murad MH, Sultan S, Haffar S, Bazerbachi F. Methodological quality and synthesis of case series and case reports. BMJ Evidence-Based Med [Internet]. 2018;23(2):60-3. Available at: http://ebm.bmj.com/lookup/doi/10.1136/bmjebm-2017-110853

10. Du R-H, Liang L-R, Yang C-Q, et al. Predictors of mortality for patients with COVID-19 pneumonia caused by SARS-CoV-2: a prospective cohort study. Eur Respir J [Internet]. 2020; 55(5):1-8. Available at: http://www.ncbi.nlm.nih.gov/pubmed/ 32269088\%0Ahttp://www.pubmedcentral.nih.gov/articlerender. fcgi?artid=PMC7144257

11. Kim ES, Chin BS, Kang CK, et al. Clinical course and outcomes of patients with severe acute respiratory syndrome coronavirus 2 Infection: a preliminary report of the first 28 patients from the Korean Cohort Study on COVID-19. J Korean Med Sci. 2020; 35(13):e142.

12. Lei Z, Cao H, Jie Y, et al. A cross-sectional comparison of epidemiological and clinical features of patients with coronavirus disease (COVID-19) in Wuhan and outside Wuhan, China. Travel Med Infect Dis. 2020;35:1-6.

13. Li X, Xu S, Yu M, et al. Risk factors for severity and mortality in adult COVID-19 inpatients in Wuhan. J Allergy Clin Immunol. 2020;S0091-6749(20)30495-4.

14. Li Y, Wang M, Zhou Y, et al. Acute cerebrovascular disease following COVID-19: a single center, retrospective, observational study. SSRN Electron J. 2020.

15. Liu K, Fang Y-Y, Deng Y, et al. Clinical characteristics of novel coronavirus cases in tertiary hospitals in Hubei Province. Chin Med J (Engl). 2020;133(9):1025-31.

16. Liu Y, Yang Y, Zhang C, et al. Clinical and biochemical indexes from 2019-nCoV infected patients linked to viral loads and lung injury. Sci China Life Sci. 2020;63(3):364-74.

17. Pan F, Ye T, Sun P, et al. Time course of lung changes on chest CT during recovery from 2019 novel coronavirus (COVID-19) pneumonia. Radiology. 2020;295(3):715-21.

18. Shen L, Li S, Zhu Y, et al. Clinical and laboratory-derived parameters of 119 hospitalized patients with coronavirus disease 2019 in Xiangyang, Hubei Province, China. J Infect. 2020;S01634453(20)30166-3.

19. Shi H, Han X, Jiang N, et al. Radiological findings from 81 patients with COVID-19 pneumonia in Wuhan, China: a descriptive study. Lancet Infect Dis. 2020;20(4):425-34.

20. Song F, Shi N, Shan F, et al. Emerging 2019 novel coronavirus (2019-nCoV) pneumonia. Radiology. 2020;295(1):210-7.

21. Chang D, Lin M, Wei L, et al. Epidemiologic and clinical characteristics of novel coronavirus infections involving 13 patients outside Wuhan, China. JAMA. 2020;323(11):1092-3.

22. Tian S, Hu N, Lou J, et al. Characteristics of COVID-19 infection in Beijing. J Infect. 2020;80(4):401-6.

23. Wang $\mathrm{D}, \mathrm{Hu} \mathrm{B}, \mathrm{Hu} \mathrm{C}$, et al. Clinical characteristics of 138 hospitalized patients with 2019 novel coronavirus-infected pneumonia in Wuhan, China. JAMA. 2020;323(11):1061.

24. Wang R, Pan $M$, Zhang $X$, et al. Epidemiological and clinical features of 125 hospitalized patients with COVID-19 in 
Fuyang, Anhui, China. Int J Infect Dis. 2020;S1201-9712(20) 30203-4.

25. Wang Z, Chen X, Lu Y, Chen F, Zhang W. Clinical characteristics and therapeutic procedure for four cases with 2019 novel coronavirus pneumonia receiving combined Chinese and western medicine treatment. Biosci Trends. 2020;14(1):64-8.

26. Wang X, Fang J, Zhu Y, et al. Clinical characteristics of non-critically ill patients with novel coronavirus infection (COVID-19) in a Fangcang Hospital. Clin Microbiol Infect. 2020;S1198-743X(20) 30177-4.

27. Pongpirul WA, Mott JA, Woodring JV, et al. Clinical characteristics of patients hospitalized with coronavirus disease, Thailand. Emerg Infect Dis. 2020;26(7):1580-5.

28. Wu J, Liu J, Zhao X, et al. Clinical characteristics of imported cases of coronavirus disease 2019 (COVID-19) in Jiangsu Province: a multicenter descriptive study. Clin Infect Dis. 2020; ciaa199.

29. Wu J, Wu X, Zeng $\mathrm{W}$, et al. Chest CT findings in patients with coronavirus disease 2019 and its relationship with clinical features. Invest Radiol. 2020;55(5):257-61.

30. $\mathrm{Xu} \mathrm{X,} \mathrm{Yu} \mathrm{C,} \mathrm{Qu} \mathrm{J,} \mathrm{et} \mathrm{al.} \mathrm{Imaging} \mathrm{and} \mathrm{clinical} \mathrm{features} \mathrm{of} \mathrm{patients}$ with 2019 novel coronavirus SARS-CoV-2. Eur J Nucl Med Mol Imaging. 2020;47(5):1275-80.

31. $\mathrm{Xu} X-\mathrm{W}, \mathrm{Wu} \mathrm{X}-\mathrm{X}$, Jiang $\mathrm{X}-\mathrm{G}$, et al. Clinical findings in a group of patients infected with the 2019 novel coronavirus (SARS-Cov-2) outside of Wuhan, China: retrospective case series. BMJ. 2020;368:m606.

32. Chen N, Zhou M, Dong X, et al. Epidemiological and clinical characteristics of 99 cases of 2019 novel coronavirus pneumonia in Wuhan, China: a descriptive study. Lancet. 2020;395(10223): 507-13.

33. Yang X, Yu Y, Xu J, et al. Clinical course and outcomes of critically ill patients with SARS-CoV-2 pneumonia in Wuhan, China: a single-centered, retrospective, observational study. Lancet Respir Med. 2020;8(5):475-81.

34. Zhang J, Dong X, Cao Y, et al. Clinical characteristics of 140 patients infected with SARS-CoV-2 in Wuhan, China. Allergy. 2020;75(7):1730-41.

35. Zheng F, Tang W, Li H, Huang Y, Xie Y, Zhou Z. Clinical characteristics of 161 cases of corona virus disease 2019 (COVID-19) in Changsha. Eur Rev Med Pharmacol Sci. 2020; 24(6):3404-10.

36. Zhou F, Yu T, Du R, et al. Clinical course and risk factors for mortality of adult inpatients with COVID-19 in Wuhan, China: a retrospective cohort study. Lancet. 2020;395(10229):1054-62.

37. Chen $\mathrm{T}, \mathrm{Wu} \mathrm{D}$, Chen $\mathrm{H}$, et al. Clinical characteristics of 113 deceased patients with coronavirus disease 2019: retrospective study. BMJ. 2020;368:m1091.

38. Chen T, Dai Z, Mo P, et al. Clinical characteristics and outcomes of older patients with coronavirus disease 2019 (COVID-19) in Wuhan, China (2019): A single-centered, retrospective study. J Gerontol Ser A [Internet]. 2020;glaa089. Available at: https:// academic.oup.com/biomedgerontology/advance-article/doi/10.1093/ gerona/glaa089/5819242

39. Chung M, Bernheim A, Mei X, et al. CT imaging features of 2019 novel coronavirus (2019-nCoV). Radiology. 2020;295(1): $202-7$.

40. Feng Y, Ling Y, Bai T, et al. COVID-19 with different severity: a multi-center study of clinical features. Am J Respir Crit Care Med. 2020;201(11):1380-8.

41. Helms J, Kremer S, Merdji H, et al. Neurologic features in severe SARS-CoV-2 infection. N Engl J Med. 2020;382:2268-70

42. Huang C, Wang Y, Li X, et al. Clinical features of patients infected with 2019 novel coronavirus in Wuhan, China. Lancet. 2020; 395(10223):497-506.

43. Gupta N, Agrawal S, Ish P, et al. Clinical and epidemiologic profile of the initial COVID-19 patients at a tertiary care centre in India. Monaldi Arch Chest Dis. 2020;90(1):193-6.

44. Filatov A, Sharma P, Hindi F, Espinosa PS. Neurological complications of coronavirus disease (COVID-19): encephalopathy. Cureus. 2020;12(3):1-6.
45. Gane SB, Kelly C, Hopkins C. Isolated sudden onset anosmia in COVID-19 infection. A novel syndrome? Rhinology. 2020;58(3): 194-6.

46. Zhang Y, Xiao M, Zhang S, et al. Coagulopathy and antiphospholipid antibodies in patients with Covid-19. N Engl J Med. 2020;382(17):e38(1)-(3).

47. Poyiadji N, Shahin G, Noujaim D, Stone M, Patel S, Griffith B. COVID-19-associated acute hemorrhagic necrotizing encephalopathy: CT and MRI features. Radiology. 2020;201187.

48. Karimi N, Sharifi Razavi A, Rouhani N. Frequent convulsive seizures in an adult patient with COVID-19: a case report. Iran Red Crescent Med J. 2020;22(3):1-3.

49. Moriguchi T, Harii N, Goto J, et al. A first case of meningitis/ encephalitis associated with SARS-Coronavirus-2. Int J Infect Dis. 2020;94:55-8.

50. Sharifi-Razavi A, Karimi N, Rouhani N. COVID-19 and intracerebral haemorrhage: causative or coincidental? New Microbes New Infect. 2020;35:100669.

51. Vu D, Ruggiero M, Choi WS, et al. Three unsuspected CT diagnoses of COVID-19. Emerg Radiol. 2020;27:229-32.

52. Wei H, Yin H, Huang M, Guo Z. The 2019 novel cornoavirus pneumonia with onset of oculomotor nerve palsy: a case study. J Neurol. 2020

53. Ye M, Ren Y, Lv T. Encephalitis as a clinical manifestation of COVID-19. Brain Behav Immun. 2020.

54. Yin R, Feng W, Wang T, et al. Concomitant neurological symptoms observed in a patient diagnosed with coronavirus disease 2019. J Med Virol. 2020.

55. Zhao H, Shen D, Zhou H, Liu J, Chen S. Guillain-Barré syndrome associated with SARS-CoV-2 infection: causality or coincidence? Lancet Neurol. 2020;19(5):383-4.

56. Gutiérrez-Ortiz C, Méndez A, Rodrigo-Rey S, et al. Miller Fisher Syndrome and polyneuritis cranialis in COVID-19. Neurology. 2020. Doi: 10.1212/WNL.0000000000009619.

57. Wu Y, Xu X, Chen Z, et al. Nervous system involvement after infection with COVID-19 and other coronaviruses. Brain Behav Immun [Internet]. 2020;87:18-22. Available at: https:// linkinghub.elsevier.com/retrieve/pii/S0889159120303573

58. Koyuncu OO, Hogue IB, Enquist LW. Virus infections in the nervous system. Cell Host Microbe [Internet]. 2013;13(4): 379-93. Available at: https://linkinghub.elsevier.com/retrieve/ pii/S1931312813001200

59. Chilvers MA, McKean M, Rutman A, Myint BS, Silverman M, O'Callaghan C. The effects of coronavirus on human nasal ciliated respiratory epithelium. Eur Respir J [Internet]. 2001; 18(6):965-70. Available at: http://erj.ersjournals.com/cgi/doi/ 10.1183/09031936.01.00093001

60. Dijkman R, Jebbink MF, Koekkoek SM, et al. Isolation and characterization of current human coronavirus strains in primary human epithelial cell cultures reveal differences in target cell tropism. J Virol [Internet]. 2013;87(11):6081-90. Available at: http://jvi.asm.org/cgi/doi/10.1128/JVI.03368-12

61. Swanson PA, McGavern DB. Viral diseases of the central nervous system. Curr Opin Virol [Internet]. 2015;11:44-54. Available at: https://linkinghub.elsevier.com/retrieve/pii/S1879625715000115

62. Klein RS, Garber C, Howard N. Infectious immunity in the central nervous system and brain function. Nat Immunol [Internet]. 2017;18(2):132-41. Available at: http://www.nature.com/articles/ ni.3656

63. Li Y, Fu L, Gonzales DM, Lavi E. Coronavirus neurovirulence correlates with the ability of the virus to induce proinflammatory cytokine signals from astrocytes and microglia. J Virol [Internet]. 2004;78(7):3398-406. Available at: https://jvi.asm.org/content/ $78 / 7 / 3398$

64. Desforges M, Le Coupanec A, Dubeau P, et al. Human coronaviruses and other respiratory viruses: underestimated opportunistic pathogens of the central nervous system? Viruses [Internet]. 2019;12(1):14. Available at: https://www.mdpi.com/1999-4915/ $12 / 1 / 14$

65. Baig AM, Khaleeq A, Ali U, Syeda H. Evidence of the COVID-19 virus targeting the CNS: tissue distribution, host-virus 
interaction, and proposed neurotropic mechanisms. ACS Chem Neurosci. 2020;11(7):995-8.

66. Jin $\mathrm{H}$, Hong $\mathrm{C}$, Chen $\mathrm{S}$, et al. Consensus for prevention and management of coronavirus disease 2019 (COVID-19) for neurologists. Stroke Vasc Neurol. 2020;5(2):146-51.

67. Bedford J, Enria D, Giesecke J, et al. COVID-19: towards controlling of a pandemic. Lancet [Internet]. 2020;395(10229):1015-8.
Available at: https://linkinghub.elsevier.com/retrieve/pii/S01406 73620306735

68. Song F, Parekh S, Hooper L, et al. Dissemination and publication of research findings: an updated review of related biases. Health Technol Assess (Rockv) [Internet]. 2010;14(8):iii, ix-xi, 1-193. Available at: https://www.journalslibrary.nihr.ac.uk/hta/ hta14080/ 